\title{
Programas de pesquisa sobre o audiovisual: anomalias em Godard e Guel Arraes ${ }^{1}$
}

\author{
Renato Luiz Pucci Jr. 2 \\ Universidade Tuiuti do Paraná \\ renato.pucci@gmail.com
}

\begin{abstract}
Resumo: Com base no conceito de programa de pesquisa científica, examinam-se anomalias enfrentadas no Brasil pela pesquisa sobre o audiovisual. Características pós-modernistas de alguns filmes da primeira fase de Godard, Uma Mulher é uma Mulher (1961) e Alphaville (1965), resultam em análises e avaliações problemáticas em pesquisas orientadas pelo programa oposicionista e no desconhecimento de vínculos cinematográficos das realizações de Guel Arraes para a TV.

Palavras-Chave: Programa de pesquisa. Audiovisual. Pós-modernismo.

Abstract: Based on the concept of scientific research program, certain anomalies presented in Brazil by the audiovisual research are analysed here. Postmodernist characteristics of some Godard's first phase films, such as A Woman is a Woman (1961) and Alphaville (1965), have led to problematic analyses and evaliations in researches guided by the oppositional program showing lack of knowledge of Guel Arraes's cinematographic links with his televisive production.
\end{abstract}

Key words: Research program. Audiovisual fiction. Postmodernism

\footnotetext{
${ }^{1}$ Trabalho apresentado no GT Fotografia, Cinema e Vídeo, no XVI Encontro da Compós, na UTP, em Curitiba, em junho de 2007.

${ }^{2}$ Doutor em Ciências da Comunicação pela ECA-USP, docente do Mestrado em Comunicação

e Linguagens da Universidade Tuiuti do Paraná
} 
Resumen: Com base en el concepto de un programa de investigación científica, se evalua anomalias en estudios brasileños a cerca del audiovisual. Las características posmodernistas de algunas películas de la primera fase de Godard, Una mujer es una mujer (1961) y Alphaville (1965), propician analisis o evaluciones que resultan problematicas. Estas suelen formar parte de investigaciones orientadas hacia el programa oposicionista y enseñan el desconocimiento de los vínculos cinematográficos de las realizaciones del director Guel Arraes para la televisión.

Palabras clave: Programa de investigation. Ficción audiovisual. Posmodernismo

Résumé : Axés sur le concept de programme de recherche scientifique, nous examinons ici les anomalies auxquelles, au Brésil, la recherche sur l'audiovisuel se trouve confrontée. Les caractéristiques postmodernes de certains films de la première phase de Godard, "Une femme est une femme» (1961) et «Alphaville» (1965), entraînent des analyses et des évaluations problématiques dans le cadre des recherches conduites par "Oppositional Program" et à la méconnaissance des relations cinématographiques des réalisations de Guel Arraes pour la télévision.

Mots-clés : Programme de recherche. Audiovisuel. Postmodernisme.

\section{O cinema e os programas de pesquisa científica}

O objetivo deste artigo é avaliar problemas enfrentados no Brasil pela pesquisa sobre cinema e TV, apontando entraves ao seu desenvolvimento e possíveis caminhos para que a recente proliferação temática das investigações se organize em torno de programas de pesquisa, de modo a evitar tanto a tendência a ignorar anomalias quanto a de abordar novos objetos com espírito antes cinefílico do que científico.

De acordo com Imre Lakatos, filósofo da Ciência (1979: 109-243), programas de pesquisa são tradições de pesquisa com regras metodológicas determinadas. Essas regras são de dois tipos: 1) a heurística negativa, que indica os caminhos a serem evitados; e 2) a heurística positiva, que define os caminhos que devem ser percorridos (ibidem, p. 161-169). Programas de pesquisa podem subsumir teorias não incompatíveis; em outras palavras, estão conceitualmente acima das teorias. 
David Bordwell (1997) trouxe esses conceitos para os estudos de cinema ao identificar, ao longo do século XX, quatro programas de pesquisa sobre os estilos cinematográficos:

a) Basic Story: contava a emergência do cinema como arte específica, num processo de acumulação técnica que o diferenciasse do teatro e da literatura: Lumière inventou o cinematografo; Méliès inventou técnicas para introduzir a fantasia; Griffith inventou a sintaxe cinematográfica etc. (ibidem, p 13-27).

b) Standard Version: narrava o desenvolvimento do cinema em direção às suas capacidades inerentes, ligadas à estética do cinema mudo (pois, dizia-se, cinema é imagem). Georges Sadoul alinhava-se a essa perspectiva (ibidem, p. 27-45).

c) Dialectical Program: propunha historiar e dirigir o caminho do cinema para a produção de representações do real. Nomes principais: Bazin e Kracauer (ibidem, p. 46-82).

d) Oppositional Program: cujo princípio organizador é a dualidade entre o cinema narrativo mainstream e a vanguarda. Objetivos: desnaturalizar as convenções do cinema clássico e sugerir modos oposicionistas em que filmes podem ser feitos. À frente, aparece o nome de Noël Burch (ibidem, p. 83-115).

Percebem-se, mesmo nas sumárias descrições acima, delimitações sobre o que é e não é válido para cada programa. A sucessão de programas se realizou sempre com a história do cinema sendo recontada de forma diferente da narrada pelo programa anterior. Para Kracauer importava o que entendia ser a propriedade básica do cinema: registrar e revelar a realidade física, preocupação não compartilhada pela Standard Version, que mostrava a evolução do cinema enquanto arte autônoma, realista ou não. A posição de Kracauer implicava valorizar determinados filmes e cineastas em detrimento de outros, com a formação de um cânone. O mesmo processo de revisão historiográfica foi efetivado pelos demais programas.

O programa oposicionista valorizou a pesquisa sobre as vanguardas e o cinema moderno, especialmente por meio do recurso que se lhe tornou típico: a 
análise fílmica. A história do cinema foi reescrita por críticos e historiadores do programa oposicionista segundo a perspectiva de que a arte deve quebrar expectativas por meio da originalidade e da crítica à representação ilusionista. $\mathrm{O}$ cinema clássico, baseado na verossimilhança, foi assumido como alvo e criticado. Em contrapartida, cada uma das variantes do cinema de vanguarda e modernista, do expressionismo alemão ao cinema experimental das décadas de sessenta e setenta, foi analisada e recebeu aprovação (BORDWELL, 1997, p. 83-115).3

A heurística negativa do programa oposicionista recusa atenção científica para o que escapa ao esquema acima delineado, a não ser para atacar o objeto de pesquisa. Eis por que em Brazilian Cinema, cuja primeira edição é dos anos oitenta, há uma desproporção abismal entre mais de cem páginas dedicadas, de um lado, a Glauber Rocha e Bressane e, de outro, cerca de dez linhas sobre Anselmo Duarte e Walter Hugo Khouri, somados (JOHNSON e STAM, 1995).

No âmbito internacional, o programa oposicionista, embora ainda atuante, foi contestado a partir da segunda metade dos anos setenta, quando o modernismo político entrou em crise. O resultado do processo foi a multiplicação de perspectivas teóricas, como o cognitivismo, os estudos culturais, as teorias da recepção etc. (MASCARELLO, 2006: 127-133).

No Brasil, o programa oposicionista ainda prevalece. Entre as causas para essa ascendência, está a importância incontestável do Cinema Novo e do Cinema Marginal junto à crítica, de modo que esta encontra dificuldade para admitir inovações teóricas que refutariam formulações enunciadas nos anos sessenta e setenta (ibidem).

Programas de pesquisa sempre enfrentam anomalias, isto é, evidências empíricas contrárias (LAKATOS, 1979, p. 146-147). Quando o programa é jovem, anomalias são apontadas, por adeptos do programa dominante, como prova de que o programa novato não é científico. Newton, por exemplo, não conseguia explicar certos fenômenos gravitacionais quando lançou sua teoria (ibidem, p. 163-167). Mas a heurística negativa do novo programa define que é mais importante preservar o seu núcleo teórico do que aceitar anomalias que o refutariam, do contrário nenhum novo

\footnotetext{
3 Repare-se no título Revisão Crítica do Cinema Brasileiro, de Glauber Rocha. Era também um trabalho revisionista, obviamente em favor do modernismo político.
} 
programa se estabeleceria, pois todos são frágeis quando dão seus primeiros passos (ibidem, p. 186). Em sua fase mais profícua, o programa estabelece um "cinturão de proteção de hipóteses auxiliares", formuladas para resguardar seu núcleo (ibidem, p. 163).

Em sua fase degenerativa, os programas de pesquisa voltam a ter sérios problemas com anomalias, pois não dão conta de ocorrências que se tornaram abundantes. Até que um novo programa, além de incorporar o que o antigo explicava, consiga, com uma "transferência de problemas teoricamente progressiva", incorporar as anomalias transformando-as em elementos corroboradores (ibidem, p. 144).

No caso brasileiro, as pesquisas sobre objetos antes ignorados produzem anomalias para o programa oposicionista: por que tantos pesquisadores se voltam de forma não-depreciativa, como tem ocorrido nos últimos anos, para campos vinculados ao cinema mainstream, como as chanchadas e os filmes de terror, se é relevante apenas o que a ele se opõe? Ignorar ou depreciar tais pesquisas pode ser uma atitude defensiva dos adeptos do programa. Com certeza, teorias e programas de pesquisa não podem ser refutados por simples anomalias (ibidem, p. 169-176), ainda mais em áreas fluidas como a da pesquisa sobre cinema. Mas, na medida em que proliferam inconsistências e hipóteses ad hoc, é possível que esteja na hora de buscar melhor concepção.

\section{Anomalias no primeiro Godard}

Há indicações de que o programa oposicionista não explica satisfatoriamente o cinema pós-moderno. Tratado como aberração, este recebeu caracterizações negativas como apolítico, não-sério, inautêntico, não-original etc. 4 Esse tratamento define o cinema pós-moderno como uma anomalia teórica.

Uma das possibilidades do estudo do pós-modernismo está na aplicação do conceito em relação a filmografias abordadas de forma insatisfatória pelo programa oposicionista. Adiante serão examinados filmes da primeira fase de Godard, de

\footnotetext{
4 Por exemplo, em PARENTE, 1998, com outros adjetivos, porém com o mesmo sentido: "estética pós-moderna, infantil e diluidora" (p. 130), "pura simulação, ao ponto de não sabermos se assistimos a um filme ou a uma publicidade de filme" (p. 131), "cinema de replicantes" (p. 131), "estética do clichê, vazia, alienante e mercadológica" (p. 134), "vazio estético" (p. 145) etc.
} 
Acossado (1959) a Made in USA (1967), identificando ocorrências que escapam à visão que a crítica desenvolveu acerca do cineasta.

Evidentemente, aquele foi um período em que Godard realizou filmes modernistas, como Viver a Vida (1962) e Uma Mulher Casada (1964), que lembram o que na época faziam Antonioni e Bergman; ou como A Chinesa (1967) e Made in USA (1967), típicos do modernismo-político. Entretanto, a grande característica de Godard era, então, a heterogeneidade entre seus próprios filmes: às realizações em tonalidade séria ou amarga, empenhadas na desfamiliarização do espectador, opunham-se Uma Mulher é uma Mulher (1961) e Alphaville (1965).

Em Uma Mulher é uma Mulher, Ângela (Anna Karina) tenta engravidar a todo custo, mesmo que tenha que embromar o namorado ou ir para a cama com um pretendente, numa paródia lúdica de comédias musicais hollywoodianas. Colorido, em cinemascope, com a graça da atriz Anna Karina jamais contrabalançada pela sórdida prostituição de seu papel em Viver a Vida, Uma Mulher é uma Mulher poderia hoje, após Guy Debord, ser chamado de espetáculo. Examine-se o tratamento concedido ao filme por seguidores do programa oposicionista.

Robert Stam considerou Godard como um dos maiores exemplos da tradição antiilusionista que ganhou com o modernismo um caráter filosófico, programático e, de alguma forma, hostil (1981, p. 22), pelo uso sistemático de recursos para quebrar a acomodação diante da ilusão de realidade. Não há o que contestar acerca dos abundantes elementos modernistas levantados por Stam em Acossado, O Desprezo (1963), Bande à part (1964), Pierrot le fou (1965), Masculino-Feminino (1966) e outros filmes de Godard, à luz do princípio brechtiano de que a arte deve revelar os princípios de sua própria construção (ibidem, p. 31). Ressalte-se, porém, a quase insignificante referência a Uma Mulher é uma Mulher:

e) esse filme constitui uma paródia e sátira reflexiva, cuja estratégia narrativa lembra Cervantes e Fielding (ibidem, p. 23).

f) Godard comparou à "escrita automática” o método improvisado que utilizara em Uma Mulher é uma Mulher, cujos trocadilhos lembram as técnicas aleatórias dos “Jogos Surrealistas" (ibidem, p. 94).

g) as gags visuais derivam de Mack Sennett (ibidem); 
h) duas linhas sobre a cena em que Ângela está prestes a entrar no chuveiro e é interrompida pelo telefone (ibidem, p. 155).

Do total, três menções limitadas à analogia com manifestações literárias ou artísticas do passado. Caso se julgue que a escassez se deva a que Uma Mulher é uma Mulher seria uma obra menor, caberia perguntar: por que "menor"?

Não é difícil de perceber que Stam teria séria dificuldade para atribuir modernismo ao filme. Trata-se de uma paródia aos musicais, no entanto está longe da "hostilidade" das paródias modernistas.5 Os recursos são antiilusionistas, pelo evidente absurdo em termos diegéticos; mesclam-se, porém, com certo respeito para com o musical, sem discursos antagônicos. Pelas marcas de ironia e por atores que não eram dançarinos ou cantores, está claro que não se pretendia emular comédias musicais; por outro lado, a tônica é de afinidade, inclusive com gags à maneira delas, como a das aberturas e fechamentos dos toldos, sinal para Ângela informar se ficará ou não com o pretendente.

Examine-se a idéia corrente de que Godard sempre se contrapôs, como bom e sério modernista, ao prazer do público acostumado à cultura de massa. $\mathrm{O}$ ataque ao prazer erótico foi um dos cavalos de batalha da crítica: "Godard utiliza diversas técnicas para sabotar o erotismo da imagem” (STAM, 1981, p. 155), afirmação válida em relação a quase todos os filmes da primeira fase, que se vão tornando mais e mais ascéticos, porém não a Uma Mulher é uma Mulher. Para corroborar a hipótese de prazer na visualização deste filme, recordem-se os planos com Anna Karina deslumbrante e sedutora, inclusive num strip-tease. Não chega a aparecer nua, o que Stam citou como prova de desinteresse de Godard pela imagem sexy (ibidem), mas nem por isso deixa de ser fascinante; sem contar que outras mulheres aparecem nuas em poses sensuais. Não há dificuldade em aplicar ao filme o que Laura Mulvey escreveu sobre o prazer masculino do olhar no cinema:

Tradicionalmente, a mulher mostrada funciona em dois níveis: como objeto erótico para os personagens da tela e para o espectador no auditório, havendo uma interação entre essas duas séries de olhares. O recurso da corista que se apresenta num palco, por

\footnotetext{
5 Um exemplo de paródia modernista: "Minha terra tem Palmares", verso de Oswald de Andrade, a investir contra o romantismo nacionalista de Gonçalves Dias. No cinema modernista, pense-se, por exemplo, na corrosiva paródia de $O$ Bandido da Luz Vermelha (Rogério Sganzerla, 1968) a programas radiofônicos.
} 
exemplo, permite que os dois olhares sejam tecnicamente unificados sem nenhuma quebra aparente da diegese (1983: p. 444-445).

Considerando-se as cenas com freqüentadores do cabaré, enquanto Ângela e suas colegas se despem, conclui-se que Uma Mulher é uma Mulher está longe de encarnar o espírito do "espetáculo interrompido". Acresce que há muito de comédia musical: olhares para a câmera, palavras dirigidas aos espectadores, trilha sonora a comentar a ação, humor leve, gags em profusão, drama romântico, happy end, aqui e ali uma cena cantada e dançada. Há elementos modernistas, por exemplo, a câmera pendular quando Ângela, por ser estrangeira, é desafiada pelo namorado a falar o "r" francês, mas poucos diante dos traços de gênero já familiares ao espectador comum. Seria necessário muito mais do que isso para interromper o espetáculo.

Outros autores de orientação oposicionista tiveram problemas semelhantes:

i) Richard Roud (1970, p. 07-13), a partir da declaração de Godard de que Uma Mulher é uma Mulher seria um "musical neo-realista: uma contradição absoluta", tentou unificar (de forma pouco convincente) a obra do cineasta por meio da idéia hegeliana de contradição.

j) Deleuze (1990) colocou Godard como um dos campeões da imagemtempo, com inúmeras referências a Acossado, Tempo de Guerra, Pierrot le Fou, Passion etc. Uma Mulher é uma Mulher recebeu apenas duas menções: 1. $^{\text {a) }}$ a de que corresponde ao gênero da comédia musical, sem subsumir a dança, mas tomando-a como limite; e $2 .^{\text {a }}$ ) para dizer que nele se passa da vida cotidiana ao teatro. São duas páginas (p. 221-223), contudo destoantes, por sua inocuidade, da caracterização heroicizante que se depreende das menções aos outros filmes. 6

k) Peter Cowie (2004, p. 61) comparou o lançamento de Acossado à primeira performance de A Sagração da Primavera, de Stravinsky, e à publicação original de Ulysses, de Joyce, isto é, às maiores manifestações modernistas do século XX. Ignora os dois longas em questão.

\footnotetext{
${ }^{6}$ Alphaville é mencionado somente uma vez, na conclusão de A Imagem-Tempo, em anódina referência de duas linhas ao sistema de poder apresentado no filme.
} 
Por sua provável influência sobre a percepção que se tem no Brasil acerca da Godard, destaque-se um dos mais importantes livros sobre cinema publicados em português: O Discurso Cinematográfico, de Ismail Xavier.7 O autor cita Acossado muitas vezes, inclusive para refutar seu suposto realismo e afirmar o caráter modernista e anticlássico do filme (XAVIER, 2005: p. 76-78) - em outras palavras, desvinculou Acossado dos parâmetros realistas do Dialectical Program e relacionouo ao Oppositional Program.

Ao abordar o impacto das ciências da linguagem sobre os estudos de cinema, os exemplos são filmes de Godard, que "não apresentam mais aquele tipo de espetáculo cuja imagem se oferecia como uma transparência reveladora dos fatos" (ibidem, p. 140). Godard foi o exemplo ao comentar a posição de Silvie Pierre, Comolli, Narboni e Garroni, que defenderam a "linguagem obscura", "contra o óbvio e o filme 'pleno de sentido'" (ibidem, p. 146). Segue-se a referência às realizações de Godard e Gorin no grupo de vanguarda Dziga Vertov (ibidem, p. 149), a partir de 1969. Em suma, a caracterização modernista parece se estender de Acossado até o final da década de sessenta, inferência problemática ao menos quanto a Uma Mulher é uma Mulher e Alphaville, não citados. Conforme dito acima, quando um programa de pesquisa é novo, seus adeptos não precisam dar conta de todas as anomalias, pois caso o tentassem o programa jamais se consolidaria. Prevalece a determinação de preservar o núcleo do programa.

No "Apêndice 1984" (ibidem, p. 172), o autor voltou ao período 1969-1972 de Godard ("cinema ascético"). No apêndice de 2005, retomou a referência ao cineasta como exemplo do "cinema moderno como campo da experiência de uma noção do tempo como rede não linear, não teleológica" (ibidem, p. 190), mencionando mais um título da primeira fase: Duas ou Três Coisas que eu Sei Dela (1966). Fica a questão: onde encaixar Uma Mulher é uma Mulher e Alphaville no quadro teórico e historiográfico indicado?8

Comparem-se as posições acima com a de um pesquisador não afeito à heurística do programa oposicionista:

\footnotetext{
7 Primeira edição em 1977.

${ }^{8}$ A listagem de autores não tem a pretensão de esgotar o levantamento, tarefa aliás impossível: nenhum cineasta teve uma fortuna crítica tão ampla quanto Godard, e, portanto, qualquer levantamento tem caráter indutivo.
} 
Trata-se, aliás, de uma trajetória perfeitamente surpreendente porque o cineasta [Godard], a princípio grande defensor de uma certa cultura industrial, a produzida em Hollywood, finalmente juntou-se aos extremos dos defensores da cultura clássica e dos menosprezadores da cultura industrial (ESQUENAZI, 2004, p. 18).

Houve, segundo o autor, um tempo em que Godard se pautava pela defesa da cultura industrial contra a "cultura clássica", ou seja, aquela que, erudita, exclui os leitores e espectadores sem repertório adequado. Eis por que alguns de seus primeiros filmes seriam marcados pela produção hollywoodiana, o que os seguidores do programa oposicionista não têm aceito, em especial no Brasil.

Durante a primeira fase de Godard, o diálogo com o cinema clássico mudou de tom, chegando à acidez de O Desprezo, Pierrot le fou e Made in USA, impondo-se as estruturas de agressão (Noël Burch), o hermetismo e a contraposição frontal àquele modo de fazer cinema. Foi essa a caracterização modernista de Godard que se perpetuou nos livros e artigos. Não era, porém, sua única face.

\section{A herança pós-modernista de Godard}

O que o mal-entendido em relação a Godard significa para os estudos do audiovisual no Brasil? Para responder à questão, deve-se pensar numa concepção mais pertinente acerca dos filmes em foco. Aqui será utilizado o referencial teórico de Linda Hutcheon sobre o pós-modernismo (1991): um fenômeno cultural fundamentalmente contraditório, por exemplo, em relação à cultura de massa, que o pós-modernismo questiona, mas não nega (ibidem, p. 22-25). O termo "paradoxal" sintetizou, para Hutcheon, esse caráter dúplice, presente na arquitetura de Las Vegas, na metaficção historiográfica (romances históricos auto-referenciais e lúdicos, como Os Filhos da Meia-Noite, de Salman Rushdie) e na Pop Art, cujo retorno ao figurativismo e a amena intertextualidade com produtos da cultura de massa põemna à parte da arte modernista.

O ponto central, que permitiu à autora olhar de forma surpreendente para realizações pós-modernistas, foi a eliminação do dualismo: o prefixo "pós" não indica a negação ou o oposto do modernismo (ibidem, p. 37). Em vez das famigeradas tabelas "Modernismo x Pós-modernismo", que elencam pares de diferenças, Hutcheon insistiu em que este é intrinsecamente paradoxal. A poética pós- 
modernista não seguiria a excludente tradição modernista do "ou... ou" ("or... or"), mas a do "e... e" ("both-and"). Em vez de "novo contra antigo" ou "arte erudita contra cultura de massa", há coexistência insolúvel de oposições (ibidem, p. 74). O pósmodernismo é paradoxal porque combina elementos modernistas e da cultura de massa, possibilitando uma aresta crítica, mas também o acesso de diversos tipos de público.

Por transitar entre o caráter espetacular e o moderno, Uma Mulher é uma Mulher pode ser chamado de pós-moderno, ao contrário de Made in Usa ou Weekend à Francesa (1967), construídos para agredir expectativas do público.

Seria possível objetar que Uma Mulher é uma Mulher está longe do tom cool que em geral se atribui ao cinema pós-moderno. Não há aquele maneirismo, que oscila entre exibir sofisticação e o uso do repertório da cultura de massa, típico do cinema pós-moderno dos anos oitenta, por exemplo em Cidade Oculta (Francisco Botelho, 1986). ${ }^{9}$ Pode-se, todavia, identificar relação entre Uma Mulher é uma Mulher e uma fração da produção televisual brasileira: os programas pósmodernistas de Guel Arraes, a partir de Armação Ilimitada. Examinem-se uma cena do filme e outra do seriado.

Em Uma Mulher é uma Mulher, quando Ângela caminha com o pretendente pelas ruas, este lhe pergunta por que está triste; Ângela dá passos rápidos e desaparece no espaço off. Escuta-se sua voz: "Porque gostaria de estar numa comédia musical...” A trilha sonora lembra a de musicais, ainda que exagerada em suas intrusões repentinas, ostensiva marca de ironia a destacar que não se trata de um verdadeiro musical hollywoodiano. Corte e Ângela reaparece com outro figurino: da blusa vermelha, saia escura e sobretudo gelo, passou para um vestido azul, gola de pele branca, e o chapéu que segurava se transformou na sombrinha vermelha. $\mathrm{O}$ penteado está mudado: de solto para preso no alto da cabeça. Ela continua: "com Cyd Charisse, Gene Kelly, coreografia de Bob Fosse". A cada nome do cinema americano, Ângela surge num local diferente, a dar ineptos passos de dança, dando à cena um ar cômico. Ao retornar à companhia do pretendente, ressurge seu figurino original, como num passe de mágica.

\footnotetext{
${ }_{9}^{9}$ Sobre esse e outros filmes brasileiros pós-modernos, v. PUCCI JR., 2003.
} 
Em Armação Ilimitada, episódio "O Pai do Bacana", Zelda Scott conversa com seu chefe na redação do Correio do Crepúsculo. Contrariada com a ordem para transformar o jornal numa "fábrica de sonhos", isto é, publicar somente notícias otimistas, ela diz: "Chefe, deixa de ser alienado. Isto aqui é Brasil!". Ele lhe responde: "Não, isto aqui é Hollywood". Após um corte, o chefe surge com uma câmera de TV, sentado a uma grua que o leva com a câmera para o alto. E continua a falar, sob uma chuva de aplausos off: "That's entertainment. The show must go on". Está ainda na redação, embora o contraplongée mostre que não há teto, mas refletores para a iluminação; em suma, revela-se o estúdio da Globo. Fusão. O próximo plano exibe Zelda e o chefe num cenário de musical americano dos anos trinta, ambos vestidos para a dança que executam ao som de Fred Astaire. Como sempre as palavras do chefe se transformaram em situações literais, mas nesta cena parodiam-se os musicais de Astaire e Ginger Rogers.

Em ambos os casos, o naturalismo foi interrompido por recursos antiilusionistas que criam o evidente absurdo em termos de realismo. Ainda que seja claro, pelas marcas de ironia e porque os atores de Godard e Arraes não são dançarinos ou cantores, que não se pretendia replicar superproduções americanas, a tônica é de afinidade com a comédia musical. Nada há da virulência da paródia modernista.

O tom leve de Armação Ilimitada, suas infinitas paródias lúdicas, a combinação de procedimentos de extração modernista com a alta comunicabilidade em relação ao público, existe também em Uma Mulher é uma Mulher. A permanência dessas características na produção televisual de Arraes ao longo dos anos noventa e seguintes impregnou a TV brasileira de programas pós-modernos (Auto da Compadecida, A Invenção do Brasil, Dias de Glória, Retrato Falado etc.) que não podem ser menosprezados a priori, sob pena de não se perceberem raízes cinematográficas ou, pior, o papel desempenhado por tais programas na sua relação com o grande público.

Essa produção faz com que o naturalismo seja minado, internamente, no mais resistente reduto da linguagem clássica, procedimento característico do pósmodernismo: solapamento de valores culturais dentro de sistemas de produção que tradicionalmente a eles aderem. Trata-se do que Hutcheon denominou caráter 
político paradoxal do pós-modernismo (1991, p. 66-73): “dentro, porém fora; cúmplice, porém crítico" (ibidem, p.103). Esse traço não tem sido entendido pela crítica que repudia essa produção, sem se dar o trabalho de examiná-la.

A rejeição se conecta com a anomalia teórica constituída pelo pósmodernismo de filmes de Godard: o desconhecimento de que Godard nem sempre foi tão revolucionário quanto se apregoa correlaciona-se com a dificuldade de enxergar na Globo uma determinada produção que não seria retrógrada.

De um lado, um dos maiores talentos do cinema, com prestígio internacional, símbolo da contestação política e cinematográfica, criador de filmes ensaísticos. De outro, um diretor lúdico e admirador da chanchada, cujo reconhecimento (quando existe) limita-se ao território nacional, com carreira na Globo, que, para boa parte da intelectualidade brasileira, é a encarnação do reacionarismo midiático. ${ }^{10}$ Caso a hipótese se sustente, Godard não ficaria diminuído, ao contrário, pois se evidenciaria que nos anos sessenta esteve sintonizado com o pós-modernismo, algo de uma precocidade assombrosa, dado que essa poética chegou ao cinema como linha de criação, isto é, com uma produção de peso, apenas nos anos oitenta, com Diva (Beineix, 1981), O Fundo do Coração (Coppola, 1982), Zelig (Woody Allen, 1983) e, no Brasil, Eu te Amo (Jabor, 1980). ${ }^{11}$

\section{Perspectivas teóricas e historiográficas}

É preciso entender o que está implicado na detecção de pós-modernismo em filmes de Godard e na produção de Guel Arraes. Quando cresce o número de anomalias e torna-se inevitável o reconhecimento do pós-modernismo, o programa oposicionista é posto em xeque, pois não se tratava apenas de negar a existência do que agora se reconhece existir: antes, indica-se a insuficiência do programa. Retornese à analogia com Newton. Não era proibida a descoberta de novos planetas, o que aliás aconteceu com Urano e Netuno: estes foram incorporados ao conhecimento científico, e as anomalias correspondentes (perturbações nas órbitas dos planetas

\footnotetext{
${ }^{10}$ Ressalte-se o mérito do Grupo de Pesquisa em Mídia e Cultura Contemporânea que tem publicado trabalhos sobre Guel Arraes, como FECHINE (2007), não submissos à heurística do programa oposicionista. Não têm, por outro lado, nenhum vínculo com a teorização aqui empreendida.

${ }^{11}$ Fique claro também que não há intenção de engrandecer Arraes com essa aproximação com Godard.
} 
conhecidos) se transformaram em corroborações do programa. No início do século XX, porém, o programa newtoniano entrou em crise e acabou substituído pela Teoria da Relatividade.

Algo semelhante ocorre na pesquisa cinematográfica: o programa oposicionista não admite que surja no horizonte nada a que se possa conceder valor, além do universo modernista: se é novo, é moderno; se não é moderno, não é novo portanto ou não existe ou é uma degeneração. Paolo Portoghesi, o arquiteto e teórico pós-modernista, descreveu esse esquema do Modernismo como a subscrição de uma "espécie de seguro sobre o seu caráter perpétuo e insubstituível". Escreveu: "Como é possível, efetivamente mudar algo que, por sua própria natureza, está em contínua mudança?". Daí a aprovação de Portoghesi ao adjetivo "pós-moderno", o único que exprime com clareza a recusa a uma certa continuidade (2002: 25-26).

Em suma, faz-se necessário um programa de pesquisa capaz de explicar não só a existência de pós-modernismo em Godard, o que seria uma parca justificativa para tanto trabalho, mas também contextualizar o próprio pós-modernismo na história do cinema e da TV.

Nada seria mais cômodo do que elevar a concepção pós-modernista à condição de programa de pesquisa e olhar para a história do cinema de acordo com seus postulados. Os ideais modernistas, como originalidade e autenticidade, passariam por falsidade, auto-ilusão, ideologia, pois nada teria jamais existido de novo e tudo seria paradoxal. Não haveria diferença, senão de grau e de consciência do processo, entre Uma Mulher é uma Mulher e A Chinesa, pois no último a ânsia pela inovação e demais anseios modernistas não constituiriam nada essencialmente diverso do pós-moderno. Fazê-lo, no entanto, seria cair naquilo que desde Lyotard os pós-modernistas sempre recriminaram nos modernistas: as grandes narrativas. Seguir-se-ia o destino das concepções que se pretendem universais: ao estender o olhar para além da produção propriamente pós-moderna, surgiria uma totalização do mesmo tipo que a renegada. A fim de evitar o passo em falso, deve-se buscar outro ponto de vista teórico.

Mais promissor parece o apresentado por Bordwell ao inventariar os programas de pesquisa. Ele assinalou o surgimento de um programa que não recria a 
história do cinema à imagem e semelhança de uma forma específica de filmes. Nessa linha, incluiu Tom Gunning, Noël Carroll, Janet Staiger, Kristin Thompson e ele próprio. Trata-se de um revisionismo historiográfico, como os que o antecederam, que não se baseia no essencialismo e no progresso linear dos estilos. A história do cinema passa a ser encarada como uma história de forças competidoras, entre elas a proposta modernista (e, acrescente-se a Bordwell, a pós-modernista), nenhuma delas definidora do que seria válido ou inválido em todos os tempos e locais (1997, p. 120127).

Nessa perspectiva, retomando a antiga formulação de Umberto Eco, os filmes-minisséries de Arraes, O Auto da Compadecida e Caramuru, a Invenção do Brasil, não seriam um sinal do fim dos tempos cinematográficos, posição apocalíptica; nem a quintessência da mídia contemporânea, posição integrada. Seriam realizações de um estilo audiovisual, entre outros, com importância cultural e histórica ainda a ser determinada.

Essa piecemeal history tem penetrado lentamente nas pesquisas feitas no Brasil, em que ainda há muito a ser feito: investigar o cinema mudo brasileiro (que não se limita a Humberto Mauro e a Limite), as comédias musicais da Cinédia, as chanchadas, a produção da Vera Cruz, os filmes dramáticos dos anos cinqüenta e sessenta (não só os de Nelson Pereira e Roberto Santos), a pornochanchada, a ficção científica nacional, o filme policial brasileiro, a relação recíproca entre cinema e TV, a recepção etc. Tudo isso começa a ser examinado, quase sempre de forma isolada, sem articulação dos pesquisadores e sem um programa de pesquisa que os oriente. Um embrião de heurística positiva define, por enquanto, que é necessário voltar a atenção para tudo o que foi deixado de lado pelo programa oposicionista, o que, além de beirar a cinefilia, é pouco para constituir um verdadeiro programa. Entretanto, parece questão de tempo o desenvolvimento nesse sentido. 


\section{Referências}

Bordwell, David. On the History of Film Style. Cambridge e Londres, Harvard University Press, 1997.

COWIE, Peter. Revolution! The Explosion of World Cinema in the 6os. Londres: Faber and Faber, 2004.

DELEUZE, Gilles. A Imagem-Tempo. São Paulo: Brasiliense, 1990.

ESQUENAZI, Jean-Pierre. Godard et la société française des années 1960. Paris: Armand Colin, 2004.

FECHINI, Yvana. Influências do Núcleo Guel Arraes na Produção Televisual Brasileira. Revista E-Compós, n. 8, abr., 2007. 14 p.

HUTCHEON, Linda. Poética do Pós-Modernismo. Rio de Janeiro: Imago, 1991.

JOHNSON, Randal; STAM, Robert. (1995). Brazilian Cinema. New York: Columbia University Press.

LAKATOS, I. O falseamento e a metodologia dos programas de pesquisa científica. In: LAKATOS, I.; MUSGRAVE, A. (orgs.), A Crítica e o Desenvolvimento do Conhecimento. São Paulo: Cultrix, 1979. p. 109-243.

MASCARELLO, Fernando. Procura-se a audiência cinematográfica brasileira desesperadamente, ou Como e por que os estudos brasileiros de cinema seguem textualistas. In: Machado Jr. et al., 2006, p. 127-133.

MULVEY, Laura. Prazer Visual e Cinema Narrativo. In: A Experiência do Cinema. Org.: Ismail Xavier. São Paulo: Brasiliense, 1983, p. 435-453.

PARENTE, André. Ensaios sobre o Cinema do Simulacro. Rio de Janeiro: Pazulin, 1998.

PORTOGHESI, Paolo. Depois da Arquitetura Moderna. São Paulo: Martins Fontes, 2002.

PUCCI JR., Renato Luiz. Cinema Brasileiro Pós-moderno: Estilo Paradoxal, em Direção a uma Poética. Tese (doutorado em Ciências da Comunicação). Escola de Comunicações e Artes - USP, 2003.

ROUD, Richard. Jean-Luc Godard. Londres: Thames and Hudson, 1970

Stam, Robert. O Espetáculo Interrompido: Literatura e Cinema de Desmistificação. Rio de Janeiro: Paz e Terra, 1981. 